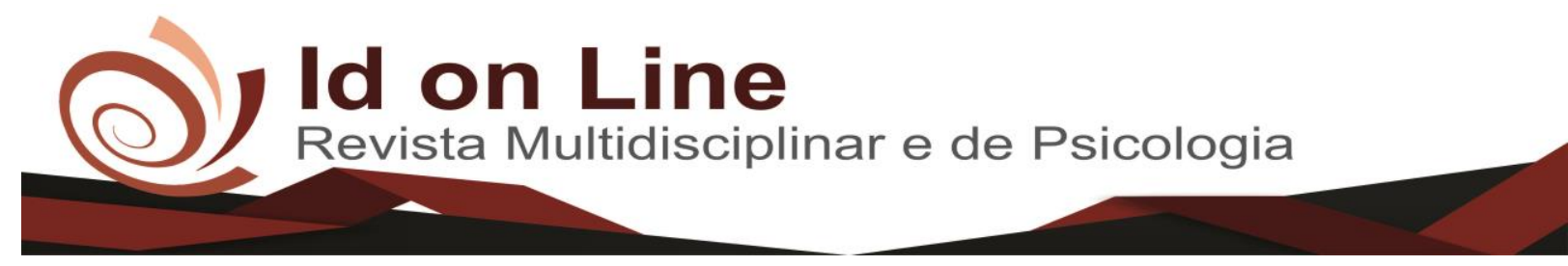

Artigo

\title{
O Processo de Terceirização de Serviços no Consórcio Águas do Ceará da Cidade de Brejo Santo-CE
}

\author{
Nauanna Sampaio Alves ${ }^{1}$; Antonia Valdelucia Costa ${ }^{2}$
}

Resumo: A terceirização é importante para as empresas uma vez que racionaliza recursos, redefine suas operações, reduz custos, além de flexibilizar e enxugar as estruturas organizacionais. Ela auxilia na reestruturação organizacional, pois promove a competividade, aumento da produtividade e a consolidação da identidade e comprometimento da empresa no mercado em que atua. O objetivo geral deste estudo foi o de conhecer os benefícios percebidos pela empresa Consórcio Águas do Ceará, localizada na cidade de Brejo Santo-CE, a partir da terceirização de serviços. Como objetivos específicos: compreender, a partir da historicidade e da conceituação de terceirização, a relevância desse processo para as empresas; evidenciar as vantagens e desvantagens da terceirização em prol da qualidade do modo de gestão atual; conceituar e destacar a quarteirização como uma ferramenta competitiva da terceirização. A fundamentação teórica abordou temas relevantes ao estudo a partir da sua historicidade e conceitos acerca da terceirização, vantagens e desvantagens deste modelo de gestão e a quarteirização como ferramenta competitiva da terceirização. Quanto à tipologia da pesquisa, adotou-se como método o estudo de caso, com base bibliográfica, de cunho descritivo exploratório, com abordagem qualitativa.

Palavras chave: Terceirização. Vantagens. Desvantagens. Quarteirização.

\section{The Outsourcing Process of Services in the Águas do Ceará Consortium of the City of Brejo Santo, State of Ceará}

\begin{abstract}
Outsourcing is important to companies, rationalizes resources, redefines operations, reduces costs, and flexibilizes and wipes out organizational structures. Thus, it assists in organizational restructuring, as it promotes competitiveness, increased productivity and the consolidation of the company's identity and commitment in the market in which it operates. The general objective of this study is to understand the benefits perceived by the company Consórcio Águas do Ceará, located in the city of Brejo Santo-CE, from outsourcing services. In addition, as specific objectives understand from the historicity and conceptualization of outsourcing the relevance of this process to the companies; to demonstrate the advantages and disadvantages of outsourcing for the quality of the current management mode; conceptualize and highlight the quarantining as a competitive tool of outsourcing. Theoretical fundamentals addressed topics relevant to the study, which includes the historicity and concepts about outsourcing, its advantages and disadvantages of this management model, and the quarantining as a competitive outsourcing tool. As for the typology of the research, the case study was adopted as a bibliographic basis, with an exploratory descriptive character, with a qualitative approach.
\end{abstract}

Keywords: Outsourcing. Benefits. Disadvantages. Quaternization.

\footnotetext{
${ }^{1}$ Concludente do Curso de Administração do Centro Universitário Doutor Leão Sampaio - UNILEÃO.

E-mail.: nauannaalves@outlook.com

${ }^{2}$ Orientadora. Prof ${ }^{a}$ Ms em Ciência da Educação pela UTIC -PY. Docente dO Centro Universitário Doutor Leão Sampaio UNILEÃO. E-mail.: valdeluciacosta@hotmail.com; valdelucia@leaosampaio.edu.br.
} 


\section{Introdução}

A terceirização é uma prática de negócio que está relacionada diretamente à competitividade, qualidade e produtividade de uma empresa. A organização que recorre da terceirização visa a redefinição do sistema operacional, a racionalização dos recursos levando à reestruturação organizacional.

A terceirização faz que com haja uma redução de custos na empresa, agilizando os serviços, aumentando a produtividade e colocando a empresa à frente de suas concorrentes. Face exposto, afirma-se que a terceirização é uma realidade consolidada e repleta de vantagens significativas para as organizações.

É uma realidade que já se encontra presente em boa parte das organizações, pois com a terceirização ocorre a descentralização das decisões. Partindo desse pressuposto, surgiu a seguinte problemática: o processo de terceirização é um caminho inevitável para qualidade da gestão de empresas? Diante do exposto teve-se como hipóteses: a terceirização é uma forma de promover qualidade para gestão das empresas? Quais elementos determinam as vantagens e desvantagens do processo de terceirização para as empresas? Como ferramenta competitiva, a quarteirização se mostra mais viável que terceirização?

Justifica-se a escolha desse tema pelo fato de que a terceirização gera a redução dos custos melhorando a qualidade de serviços e da gestão da empresa contratante, fazendo com que esta esteja à frente das suas concorrentes. Além do fato de a que se "mal" gerido, o processo de terceirização provoca mais desvantagens que vantagens, fator determinante para o sucesso e/ou fracasso de uma organização.

Ao se buscar compreender e responder a problemática e as hipóteses da pesquisa, foi traçado como objetivo geral: conhecer os benefícios percebidos pelos gestores da empresa Consórcio Águas do Ceará, a partir da terceirização promovida durante a obra. Partindo da generalidade, os objetivos específicos foram: compreender a terceirização à partir da historicidade e a sua conceituação bem como a relevância desse processo para as empresas; evidenciar as vantagens e desvantagens da terceirização em prol da qualidade do modo de gestão atual; conceituar e destacar a quarteirização como uma ferramenta competitiva da terceirização.

O estudo de caso foi realizado no Consórcio Águas do Ceará, localizado na cidade de Brejo Santo- CE, e através da coleta e análises dos dados, visou-se compreender e evidenciar 
como se deu o processo de terceirização a partir das perspectivas dos entrevistados, que atuam na gestão da empresa.

\section{Referencial Teórico}

\section{Breve Contextualização Histórica Sobre a Terceirização}

Para uma melhor compreensão de como se dão os processos econômicos, sociais e culturais da sociedade é necessário que se mergulhe no passado, a fim de entender, evoluir e melhorar o presente (MACHADO et.al, 2006). Desse modo, é essencial que se faça uma breve contextualização histórica sobre a terceirização com o objetivo de fundamentar a discussão acerca do tema estudado.

De acordo com Leiria e Saratt (2005, p. 15), a terceirização teve sua origem na década de 1940, durante a: “[...] Segunda Guerra Mundial e foi iniciada nos Estados Unidos [...]”, época em que as tropas do país foram enviadas para participar da guerra, e o setor industrial não conseguiu suprir as necessidades do mercado. Com o objetivo de atender a demanda excessiva, optou-se por transferir para terceiros, atividades relacionadas ao suporte. Desse modo, foi possível abastecer o mercado, aprimorando técnicas de produção e produtos.

Neste sentido, Delgado e Henrique (2004, p. 11) destacam que a Segunda Guerra Mundial é: "[...] marco histórico mais importante da terceirização [...]", pois o processo de terceirização das industrias interferia diretamente na economia e na sociedade e passou a ser tema de estudo de diversas áreas de conhecimento, tais como o Direito e a Administração.

No Brasil “[...] a noção de terceirização foi trazida pelas multinacionais por volta de 1950, pelo interesse que tinham em se preocupar apenas com a essência do negócio [...]" (DIEESE, 2003, p.30). As primeiras empresas focadas em atividade de conservação e limpeza, se tornam as pioneiras no processo de terceirização. E até o ano de 1967 conseguiram reduzir os custos de contratação de mão de obra, sem que isso afetasse a gestão da empresa, proporcionando lucros e sem violar as leis trabalhistas.

Ainda de acordo com o DIEESE (2003, p.30), a terceirização de prestação de serviços e de produção no território nacional, cresceu consideravelmente devido as urgências do capitalismo. Tal fato foi proporcionado pela: “[...] terceira Revolução Industrial iniciada na década de $1970[\ldots]$ ”, provocou a necessidade de se reestruturar os meios de produção e de 
trabalho por meio da terceirização. Esse movimento se estendeu até a de 1980 e se consolidou na década de 1990.

Para Pochmann (2007, p.21), com a “[...] intensificação do fenômeno da globalização na década de 1990, devido a economia ao mercado exterior [...]”, com o auxílio da terceirização, devido aos problemas econômicos que o país passava. Tal prática impulsionou a competividade e produtividade das empresas em todos os setores da economia brasileira. Mesmo que o processo de crescimento econômico tenha sido lento, a terceirização contribuiu e ainda contribui para reduzir e descentralizar os riscos de produção e de serviços.

De acordo com Machado et.al (2006, p.8), a terceirização no século XXI além de causar a reestruturação de produção e de serviços nas empresas vem realizando o: “[...] desmonte das grandes estruturas verticalizadas, possibilitando a criação e multiplicação do número e prestadores de serviço [...]". Atualmente, as atividades ligadas a terceirização promovem a eficiência da gestão empresarial em todos os setores do mercado.

É possível afirmar que a terceirização se faz essencial no mundo globalizado e contribui de forma contundente com a empregabilidade no país.

\section{Conceituando a Terceirização}

Segundo Delgado (2012, p.407), a terceirização é expressão que resultou do “[...] neologismo vindo da palavra terceiro, que é entendido como interveniente, intermediário [...]". Tal conceituação pode ser interpretada como um procedimento e/ou método de gestão administrativa descentralizadora de atividades. Neste sentido, Gonzaga e Nazar (2016, p. 23) apontam que a terceirização pode ser entendida como:“[...] a contração de mão de obra através de empresa interposta [...]”, ou seja, uma organização contrata a mão de obra por intermédio de terceiros, e acaba intervindo na produção e prestação de serviços.

Já Cassar (2013, p. 480) conceitua terceirização como um: “[...] um mecanismo jurídico que permite a um sujeito de direito tomar serviços no mercado de trabalho sem ser diretamente responsável por forma um vínculo empregatício com os trabalhadores [...]”. O autor ressalta que a terceirização é dissociação da relação "justrabalhista" com a relação econômica que normalmente estabelecem no mercado de trabalho.

Mendonça (2008, p.19) diz que a terceirização: “[...] é o ato pelo qual a organização contratante, mediante contrato, entrega a outra organização certa tarefa, atividade e/ou serviço 
não incluídos nos fins sociais da organização [...]”. Desse modo, “[...] o trabalhador é inserido na empresa tomadora de serviço, mas seus laços trabalhistas permanecem na empresa fornecedora de serviço [...]” (KARDEC; CARVALHO, 2007, p. 19).

Ainda neste sentido, Giosa (2008, p.45) afirma que a terceirização: “[...] estabelece uma relação de parceria [...]", dado que alguns dos serviços e funções são repassados a terceiros, enquanto os gestores e colaboradores da empresa (contratante) se concentram nos afazeres ligados diretamente ao mercado.

Torna-se possível simplificar o conceito sobre a terceirização, ao citar a importância da qualidade do serviço oferecido pelas empresas. Para Martins (2012, p. 17), “[...] as empresas terceirizadas são aquelas que tomam parte em um processo de terceirização, na qualidade de contratadas, tanto na prestação, quanto no fornecimento de produtos, participando ativamente nessas questões [...]".

Tal conceito reforça a ideia de se estabelecer uma parceria entre a empresa contratante e a contratada, no sentido de aturem como uma única unidade empresarial, em prol do crescimento da empresa.

\section{Vantagens e Desvantagens da Terceirização}

Atualmente três aspectos estimulam o crescente processo de terceirização: “[...] a globalização, os avanços tecnológicos e a clientela inconstante e exigente [...]” (GIOSA, 2008, p.29). A soma desses aspectos leva as empresas a terceirizar atividades, estimula a competitividade por meio da livre concorrência, tendo como objetivo e base a qualidade dos serviços ofertados a sua clientela. Isso acarreta diretamente na eficácia e eficiência operacionais da organização empresarial, fazendo com ela permaneça no mercado no qual atua.

De acordo com Mendonça (2008, p.22), as principais vantagens da terceirização são:

[...] Minimização dos desperdícios e perdas, através da otimização de recursos; reduz os custos administrativos, de pessoal e as reclamações trabalhistas; Gera maior agilidade nas decisões. Otimiza o uso de espaços (áreas físicas); Gera melhoria na administração do tempo para gestão do negócio; aumenta a oferta de emprego; Promove o desenvolvimento econômico.

O fato de uma empresa terceirizar certas atividades não leva a ideia de que seus gestores são incapazes de gerir e contratar mão de obra para exercer certas funções. Percebe-se que o 
foco é essencialmente tornar a gestão mais eficiente e que traga vantagens significativas à empresa, colocando-a à frente de suas concorrentes.

No que se refere às desvantagens da terceirização, Leiria e Saratt (2005, p.34) destacam que são:

Demissão na fase inicial; Diminuição dos postos de trabalho; Custo das demissões; Redução dos salários e aumento da jornada de trabalho, diminuição dos benefícios e das condições de trabalho na empresa terceira; Possibilidade de queda de qualidade dos serviços ou atividades terceirizadas, gerando um risco empresarial; Depreciação das relações trabalhistas; Aumento da dependência de terceiro.

Já Delgado e Henrique (2012, p.28) chamam as vantagens e desvantagens da terceirização como acertos e falhas. Dentre as principais vantagens, além das já citadas por outros autores, eles destacam ainda: “[...] maior agilidade nas decisões, menor custo, maior lucratividade e crescimento; focalização dos negócios da empresa na sua área de atuação; e diminuição da ociosidade das máquinas, maior poder de negociação, ampliação do mercado para as pequenas e médias empresas [...]”; no que refere as desvantagens eles apontam: “[...] risco de desemprego e não absorção da mão-de-obra na mesma proporção; Resistências e conservadorismo; falta de parâmetros de custos internos; aumento da dependência de terceiros; e desconhecimento da legislação trabalhista [...]".

Diante do exposto, nota-se que a terceirização deve ser bem planejada, a fim de que as desvantagens não se sobressaiam sobre as vantagens.

Para Kardec e Carvalho (2007), quando a terceirização é feita de maneira precipitada e não devidamente planejada, a gestão da empresa contratante passa a se preocupar em gerir atividades de responsabilidade da empresa contratada, e demonstra que buscar por terceirizar determinadas atividades se deu apenas com objetivos de reduzir custos, deixando a qualidade de lado.

Neste sentido Girardi (2006, p.25) afirma que isso leva à: “[...] perda de controle da empresa tomadora em relação ao conhecimento da técnica envolvida nos processos de terceirização [...]". Tal afirmação leva a pensar que muitos gestores possuem pouco conhecimento sobre a terceirização. Isso faz com que a gestão seja prejudicial aos objetivos da empresa em crescer e desenvolver um trabalho e/serviço de qualidade. 


\section{Quarteirização: Uma Vantagem Competitiva da Terceirização?}

Devido a um grande número de empresas que veem fazendo uso da terceirização, surgiu a quarteirização, que segundo Machado et.al (2006, p. 5) é: “[...] um fenômeno novo, que consiste na contratação de uma empresa especialista para gerenciar a parceria que se estabelece entre as empresas envolvidas na terceirização [...]". Mesmo o termo, assim como a prática da quarteirização sendo conhecida desde da década de 1990, o seu processo é pouco usado pelas empresas.

Já Mendonça (2008, p.27) afirma que a quarteirização é: “[ [... extrema importância para o acompanhamento, verificação da qualidade e monitoramento das empresas terceirizadas [...]". Para Silveira et.al (2002, p.36), a quarteirização deve ser tratada como “[...] uma excelente ferramenta na administração do risco jurídico da terceirização [...]", dado que, segundo o autor, a empresa responsável pela quarteirização visa evitar que haja um desgaste entre as empresas parceiras na terceirização.

Para Caldeira (2018, p. 01), a quarteirização é a

[...] contratação de uma empresa terceira, que tem como finalidade coordenar, com maior qualidade, todos os contratos de terceirizados existentes. Ressaltando que além da melhoria na gestão, o desgaste entre a contratante e terceiros fica minimizado pela presença desta gestora, formando um "colchão" para absorver parte dos problemas.

Cabe destacar, que a quarteirização nasceu da necessidade de se resolver os principais problemas que surgem do processo de terceirização, ou seja, “[...] o problema burocrático e o técnico [...]" (MACHADO et.al., 2006, p. 6). O primeiro ocorre devido a número de contratos de terceirização e dificuldade e/ou incapacidade da empresa em geri-los. O segundo, se refere a falta de conhecimento técnico do cliente sobre o que é produzido e realizado por terceiros, fazendo com que não se consiga avaliar devidamente o trabalho que é realizado.

Queiroz (2004, p.140) enxerga a quarteirização como a: “[...] vanguarda da terceirização, um processo evolutivo que vai permitir que mais empresas se criem [...]”; o objetivo seria o de provocar o aperfeiçoamento da gestão e gerar a criação de mais empregos.

Para Gimenes et.al (2016, p.8), a quarteirização não é totalmente uma evolução da terceirização e sim uma "[...] ferramenta especializada para resolução de problemas surgidos no processo de terceirização [...]”. Quarteirizar seria buscar pela especialização, pela qualificação, visando a melhor maneira de gerenciar essa parceria sem que as empresas envolvidas tenham qualquer tipo de prejuízo que não possa a vir ser solucionado. 
No quadro 1 a seguir, é possível constatar as principais diferenças entre a terceirização e quarteirização.

Quadro 01: Diferença entre Terceirização e Quarteirização.

\begin{tabular}{|c|c|}
\hline TERCEIRIZAÇĀO & QUARTEIRIZAÇÃO \\
\hline $\begin{array}{l}\text { Tem como princípio básico a delegação } \\
\text { para terceiros de todas as atividades que } \\
\text { a empresa considerar estar fora de sua } \\
\text { vocação, transferindo processos e } \\
\text { funçōes específicas a empresas ou } \\
\text { profissionais especializados que possuem } \\
\text { o domínio operacional e técnico da } \\
\text { atividade terceirizada. }\end{array}$ & $\begin{array}{l}\text { A quarteirização surge, como alternativa } \\
\text { para alavancar os ganhos provindos da } \\
\text { terceirização, eliminando o inchaço da } \\
\text { estrutura interna das empresas, } \\
\text { estabelecendo uma maior agilidade e } \\
\text { pró -atividade na solução dos eventuais } \\
\text { conflitos do relacionamento. }\end{array}$ \\
\hline
\end{tabular}

Fonte: Gimenes et.al (2016).

A terceirização é uma forma de gerir atividades e serviços, já a quarteirização é uma alternativa, uma clara ferramenta competitiva (CARNEIRO, 2016), onde é definido a função de cada empresa na terceirização, e é feito o acompanhamento desse processo a fim de poder atender às necessidades de ambas as empresas.

Diante do exposto, percebe-se a importância da terceirização tanto para as empresas como para a economia (GIRARDI, 2006). Tal aspecto faz com que o tema seja de fundamental interesse para o processo de administração e gestão de uma empresa. Devido a isso, os conceitos e teorias trazidos nesse referencial teórico, são essenciais para as análises e compreensão mais aprofundado sobre o tema investigado.

De acordo com Caldeira (2018, p. 01),

Os contratos terceirizados passam a ser geridos por uma terceira empresa especializada, um profissional autônomo ou até mesmo um profissional da própria organização destinado apenas para este fim, de forma que a organização possa concentrar esforços em sua atividade principal.

Logo, para alguns estudiosos, a quarteirização é vista como a evolução do processo de terceirização, onde o empregado é gerenciado por uma quarta empresa, já que a quarteirização trata-se de uma terceira empresa na relação trabalhista (CALDEIRA, 2018). 


\section{A Nova Lei da Terceirização}

A lei 13.429 de 2017, conhecida como a nova lei da terceirização, veio possibilitar que as: "[...] empresas possam fazer uso da terceirização da mão de obra, mesmo em caso da atividade fim [...]" (BARRETO, 2017, p.13). A lei procura modernizar as relações de trabalho, pois terceiriza as atividades (fins ou meios) das empresas contratantes, fazendo com que elas se tornam responsáveis por subsidiar os débitos trabalhistas da terceirizada.

De acordo com Dias (2017, p.20), a nova lei promove a: “[...] vulgarização das relações trabalhistas preconizando a situação jurídica do empregado [...]”; tal prerrogativa levaria a contratação de empregados terceirizados por salários menores, consequentemente a supressão de alguns de seus direitos. Em contrapartida a alteração proposta na lei 13.429/2017 geraria mais empregos o que levaria ao aquecimento da economia nacional.

O Tribunal Superior do Trabalho - TST- na súmula 331, que vigorava antes da lei 13.429/2017, estabelecia que: “[...] a contratação de trabalhadores por empresa interposta é ilegal [...] salvo o caso de trabalho temporário [...]" (SOUZA, 2017, p.29), dado que isso criava um vínculo empregatício com a empresa contratante, levando a eliminação do vínculo entre a empresa terceirizada e o terceirizado, tal ato tornaria a terceirização uma ação ilícita.

Para a 4a Turma do Tribunal Regional da Terceira Região (TRT-03-RO) a:

[...] contração terceirizada, por si só, não representa violação direta à legislação trabalhista, quando permite o repasse de atividades periféricas e/ou intermediárias, promovendo com isto um incremento na oferta dos postos de trabalho. Entretanto, quando os serviços terceirizados estão intrinsecamente vinculados à atividade-fim do tomador; que o trabalhador terceirizado executa as mesmas atividades desenvolvidas pelos empregados do banco tomador dos serviços, lado a lado com estes, além de estar subordinado diretamente aos prepostos do respectivo tomador dos serviços, tem-se por desvirtuado o instituto da terceirização, que não pode servir de instrumento para alijar o trabalhador das vantagens concedidas aos empregados do tomador de serviços e das garantias creditórias por ele ofertadas (DIAS, 2017, p.21).

Neste sentido, se estabelece a ideia de que o trabalhador terceirizado por cumprir as mesmas funções e trabalhar ao lado dos trabalhadores não terceirizados, em tese deveria ter os mesmo direito, vantagens e garantias. A nova lei reconhece a existência desses direitos e reforça que há um vínculo empregatício entre a empresa contratante e os empregados terceirizados.

Portanto, quanto é verificado que o trabalhador terceirizado se encontra subordinado diretamente a empresa contratante, ele passa atender aos requisitos jurídicos das leis trabalhistas 
clássicas. O não atendimento a essas leis faz com que terceirização seja desvirtuada, quando é comprovado o vínculo empregatício com a empresa contratante.

\section{Metodologia}

\section{Caracterização da Pesquisa}

O presente estudo trata-se de uma pesquisa bibliográfica, descritiva, de abordagem qualitativa através de um estudo de caso.

A pesquisa é bibliográfica uma vez que será desenvolvida com base em material já elaborado e publicado de diversos autores sobre o tema. Os resultados da pesquisa bibliográfica serão expostos e discutidos no referencial teórico do presente estudo (GIL, 2008).

Sobre o caráter descritivo da pesquisa, pode-se afirmar que a mesma realizou-se com a descrição das características da população estudada, de forma a descobrir as variáveis de pensamentos dos objetos de estudo (GIL, 2008), baseando-se nas falas dos entrevistados sobre os aspectos referentes ao processo de terceirização ocorrido no Consórcio Águas do Ceará CAC I, situado na cidade de Brejo Santo, interior do Estado do Ceará.

A abordagem qualitativa deste estudo, conforme Triviños (2008, p. 131), é caracterizada de maneira geral como "[..] a rota ser seguida em uma investigação. Isto é, existe uma escolha de um assunto ou problema, uma coleta de dados e análise das informações". Sendo assim indispensável ao pesquisador fornecer esclarecimentos importantes sobre o tema abordado.

Sendo este um Estudo de Caso, Triviños (2008, p.120) o define como: “[...] atividades de investigação que podem ser denominadas específicas e [...] caracterizadas por traços comuns". Desse modo, buscar-se-á compreender o processo de terceirização do Consórcio Águas do Ceará, ao evidenciar as principais vantagens e desvantagens que ocorreram durante esse processo.

\section{População e Amostra da Pesquisa}

A população de amostra desse estudo foi composta por quatro participantes que trabalham no Consórcio Águas do Ceará, ocupando cargos ligados à gestão da obra e atuam no processo de terceirização da empresa.

561 Id on Line Rev. Mult. Psic. V.12, N. 42, , Supl. 1, p. 552-568, 2018 - ISSN 1981-1179 


\section{Instrumento de Coleta de Dados}

Os meios utilizados para obtenção das informações objetos desta investigação seguiram os princípios metodológicos propostos. $\mathrm{O}$ instrumento mais adequado para a pesquisa em questão foi a entrevista semiestruturada que, conforme Silva e Silveira (2007, p. 15), caracterizam-se pela forma em que se é realizada através de "[...] perguntas abertas, feitas oralmente em ordem prévia, mas na qual o entrevistador poder acrescentar questões de esclarecimento ou instigar as respostas do entrevistado". As questões abordaram aspectos relevantes ao tema estudado e estão de acordo com os objetivos traçados para esse estudo.

A entrevista também conteve questões com: “[...] um conjunto de respostas (dentre as quais o entrevistado deve escolher a que melhor corresponde a sua opinião) [...]” (SILVA; SILVEIRA, 2007, p. 15).

\section{Técnicas de Análise dos Dados}

A análise do conteúdo foi empírica e direcionada para a interpretação, tendo como base o conteúdo analisado. A análise tem que "vestir" o conteúdo de acordo com as regras que a embasaram (BARDIN, 2011).

A análise realizada focou-se nas percepções e nos significados que permitiram inferir e ampliar os conhecimentos já conhecidos sobre o tema (FERREIRA, 2003).

\section{Aspectos Éticos da Pesquisa}

A presente pesquisa seguiu as determinações descritas e contidas na resolução 510/2016, uma vez que pesquisas na área de ciências humanas sociais exigem a garantia da manutenção do respeito e dos direitos dos participantes da pesquisa. Isso se justifica devido ao risco em que o estudo pode levar aos participantes da pesquisa a passarem por algum tipo de constrangimento, desconforto ou qualquer tipo de sintoma que afete sua integridade física e psicológica (BRASIL, 2016).

De acordo com a resolução acima citada, o autor da pesquisa deixar suficientemente claro todo o conteúdo da pesquisa à medida da compreensão do participante, respeitando 
sempre sua particularidade, privacidade, a natureza e finalidade da pesquisa e demais aspectos relacionados a ela.

\section{Resultados e Discussão}

A presente seção discorre sobre a análise dos dados obtidos com a pesquisa de campo realizada em uma das sedes das obras da transposição do Rio São Francisco, o Consórcio Águas do Ceará - CAC I, situada na cidade de Brejo Santo-CE.

Em conformidade com a metodologia proposta, a pesquisa deu-se por meio de uma entrevista semiestruturada direcionada a quatro membros de setores administrativos diversos responsáveis ou ligados a processos de terceirização de serviços.

Os participantes da pesquisa em sua maioria são profissionais especializados em suas funções, com formação acadêmica, vasto conhecimento em sua área de formação e grande experiência em tempo de atuação, com exceção de apenas um participante, que ainda está a concluir o curso superior. Entretanto, possui um tempo considerável no exercício de sua função, o que torna fundamental seu papel na organização.

Quando indagados sobre quais os principais motivos que os levou à decisão de terceirizar serviços, a resposta de que foi devido à redução de custos é quase unanime, o que confirma a fala de Mendonça (2008, p.22) quando diz que "a terceirização reduz os custos administrativos e de pessoal". Mas também, as respostas dos entrevistados levaram a outras conclusões acerca do processo de terceirização, como por exemplo: a contratação de mão de obra de serviços especializados, que tem por objetivo principal tornar a gestão administrativa mais eficiente; a velocidade na execução das atividades, onde o foco é otimizar os processos administrativos e gerenciar o tempo a favor da organização nas tomadas de decisão.

No que tange aos benefícios trazidos para o CAC I com a terceirização, ocorreu o mesmo com a questão anterior, quase uma unanimidade ao afirmaram que a principal vantagem é a diminuição de custos operacionais, onde mais uma vez Mendonça (2008, p.22) estava certo ao afirmar que: “[...] minimização dos desperdícios e perdas, através da otimização de recursos; reduz os custos administrativos, de pessoal e as reclamações trabalhistas; gera maior agilidade nas decisões [...]" são as principais regalias adquiridas com a terceirização. Outras respostas dos pesquisados também entram em concordância não apenas com Mendonça (2008), mas também com Delgado e Henrique (2012) quando se trata da agilidade nos processos, tomadas de decisão e execução de atividades. Ainda pode se constatar na pesquisa que o bom 
relacionamento entre os funcionários do CAC I e os colaboradores terceirizados é também uma grande vantagem desse processo.

Por outro lado, foram constatadas inúmeras desvantagens em face da terceirização de serviços no CAC I, por parte dos entrevistados. Uma das principais insatisfações evidenciadas foi o aumento da dependência de serviços prestados pelos terceirizados, fenômeno citado por Leiria e Saratt (2005) onde esse ainda destaca outros prejuízos ligados a terceirização, como por exemplo, a diminuição de postos de trabalho que leva a demissão em massa que leva a gastos com as demissões. Mas a maior desvantagem, segundo os entrevistados, é o mau relacionamento com os sindicatos trabalhistas, porém, a Lei 13.429/17 garante que "[...] as empresa possam fazer uso da terceirização da mão de obra, mesmo em caso da atividade fim [...]” (BARRETO, 2017, p.13), e a 4a Turma do Tribunal Regional da Terceira Região (TRT03-RO) afirma que: “[...] a contração terceirizada, por si só, não representa violação direta à legislação trabalhista, quando permite o repasse de atividades periféricas e/ou intermediárias, promovendo com isto um incremento na oferta dos postos de trabalho [...]", ou seja, por mais desconfortável que seja a situação para eles, a terceirização não causa nenhum problema relacionado a legalidade da prática. E uma última desvantagem relatada foi a mudança na estrutura organizacional da empresa; esse fato se dá em virtude da inclusão de funcionários de outra organização com características, clima e cultura organizacional diferentes.

De acordo com as respostas dos participantes da pesquisa, os principais obstáculos enfrentados no processo de terceirização de serviços estão ligados a questões trabalhistas, normas internas e obediência à regras da CLT - Consolidação das Leis do Trabalho. Os mesmos afirmam que as empresas terceirizadas apresentam dificuldades para seguir as diretrizes estabelecidas pelo Consórcio, e ainda, em alguns casos, as empresas terceirizadas não oferecem o serviço com a qualidade esperada pelo contratante o que acarreta em problemas de planejamento na gestão.

Ao serem questionados sobre quais recomendações sugeririam aos gestores que planejam terceirizar algum tipo de serviço em suas empresas, todos os entrevistados foram categóricos em suas respostas quando afirmaram que é necessário, além de muito planejamento, é preciso também conhecer todo o processo legal de terceirização para garantir que essa esteja cumprindo com todas as obrigações trabalhistas, a fim de evitar prejuízos e problemas judicias junto à Justiça do Trabalho contra a empresa contratante. Outro detalhe importante que fora levantado pelos pesquisados, é o fato da pesquisa de mercado, ou seja, é necessário que a empresa que deseje terceirizar seus serviços precisa estar atenta às ofertas das empresas dentro 
do mercado, visando a contratação de um serviço mais barato, entretanto com qualidade, portanto, um serviço com eficiência.

Quando se foi perguntado sobre suas opiniões em relação aos serviços que deveriam ser terceirizados, foi possível perceber que as opiniões estão divididas. Enquanto alguns concordam justificando que a terceirização deve acontecer no intuito de reduzir custos e melhorias na qualidade do serviço prestado, por empresas especialistas na área, outros justificam sua oposição com o argumento de que muitos terceirizados não se comprometem em oferecer ou prestar o serviço com a qualidade, exigência e comprometimento desejado pela empresa contratante ou quando há riscos de a empresa contratante mover ações trabalhistas contra o Consórcio por motivos diversos.

E por fim, quando perguntados sobre o que pensavam sobre terceirizar mais serviços além dos já terceirizados, as opiniões mais uma vez ficaram divididas. Enquanto que por um lado as opiniões a favor se baseiam em argumentos de que os serviços que demandem mais especialização devem sim ser terceirizados. Por outro lado, a opinião dos entrevistados que se opõem é com base em que as atividades fim devem ser realizadas pelo próprio Consórcio, visando manter o alto padrão de qualidade na prestação de serviço, além da justificativa de que, em alguns casos, os serviços já terceirizados suprem a necessidade do Consórcio e com isso descartando a possibilidade de novas terceirizações.

\section{Considerações Finais}

A princípio foi possível perceber que o processo de terceirização é uma prática muito conhecida pelos gestores da empresa utilizada como objeto de estudo. Muito embora os entrevistados possuam formações acadêmicas diversas, isso não foi problema para dar seguimento com a pesquisa, pois os mesmos apresentaram um alto nível de conhecimento e familiaridade com a terceirização, o que facilitou e beneficiou bastante a obtenção dos dados, uma vez que foi possível entender a terceirização de diversos pontos de vista sob aspectos de diferentes áreas de conhecimento.

Conforme enunciado no referencial teórico deste trabalho, o processo de terceirização é uma prática de negócio que está relacionada a competitividade, produtividade da empresa e qualidade de produtos ou serviços, visando sempre a otimização dos serviços e redução de 
custos. A terceirização, conforme Queiroz (2004), estimula a mudança de comportamento das organizações de modo que suas ações sejam sempre pautadas no benefício comum.

A partir dos resultados obtidos na pesquisa de campo juntamente ao levantamento bibliográfico feito nesse trabalho, é possível concluir que as principais vantagens do processo de terceirização para as empresas se dá pelo fato da considerável redução de custos, agilidade na prestação de serviços bem como a manutenção da qualidade, uma vez que determinados serviços são terceirizados devido a sua complexidade e a existência de empresas especializadas em determinadas áreas de serviço. Isso mostra que os principais objetivos da pesquisa foram atingidos e consequentemente, as hipóteses levantadas pelo autor, foram confirmadas.

Por outro lado, existem algumas desvantagens que precisam ser levadas em consideração, como por exemplo, as questões trabalhistas, onde a empresa contratante deve atentar-se ao processo legal a fim de evitar ocasiões desconfortáveis junto a justiça do trabalho. Outro exemplo comum é a dependência de serviços prestados por terceiros, esse detalhe é muito importante de que as empresas não podem negligenciar, para não correrem o risco de delegar atividades crucias, como exemplo característico, atividades fim.

Portanto, a pesquisa conclui que o processo de terceirização de serviços das empresas, sobretudo ao Consórcio Águas do Ceará - CAC I, é uma prática estratégica que visa um diferencial competitivo no mercado global, prática essa que, embora possua obstáculos, mostrase ser uma estratégia muito vantajosa e muito benéfica aos processos administrativos internos.

\section{Referências}

BARDIN, Laurence. Análise de conteúdo. Lisboa: Edições 70, 2011.

BARRETO, Glaucia. Curso de Direito do Trabalho. Niterói: Impetus, 2017.

BRASIL. Lei 13.429/2017. Lei da Terceirização e do Trabalho Temporário. Disponível em: http://www.planalto.gov.br/ccivil_03/ ato2015-2018/2017/lei/113429.htm. Acesso em: 20 de Julho de 2018.

BRASIL. Resolução $\mathbf{n}^{\mathbf{5}} \mathbf{5 1 0}$ de 07 de Abril de 2016. Disponível em: http://conselho.saude.gov.br/resolucoes/2016/reso510.pdf. Acesso em: 05 de Julho de 2018.

CALDEIRA, Francisco Paulo. Quarteirização - Você sabe o que é? Disponível em: $\langle$ https://www.contabeis.com.br/noticias/14600/quarteirizacao-voce-sabe-o-que-e/> Acesso m 30 Out. 2018. 
CASSAR, Vólia Bonfim. Terceirização. In: Direito do Trabalho. 8. ed. São Paulo: Método, 2013. cap. 15, p 479-51. v. 1.

DELGADO, G.N. HENRIQUE, C.A.J. Terceirização no direito do trabalho. Belo Horizonte: Mandamentos, 2004.

DELGADO, M. G. Curso de Direito do Trabalho. 10. ed., São Paulo: LTr, 2012.

DIAS, Eliezer Coelho. A nova lei da terceirização 13.429/2017. Disponível em: $<$ http://www.conteudojuridico.com.br/artigo,a-nova-lei-da-terceirizacao-do-trabalho-lein\%C2\%B0134292017,590073.html>. Acesso em: 28 de setembro de 2018.

DIEESE, 2003. Relatório Técnico: O Processo de Terceirização e seus Efeitos sobre os Trabalhadores no Brasil. Disponível em: http://ftp.medicina.ufmg.br/osat/arquivos/607082015.pdf. Acesso em: 15 de Junho de 2018.

FERREIRA, M. C. (2003). O sujeito forja o ambiente, o ambiente "forja" o sujeito: mediação indivíduo-ambiente em ergonomia da atividade. In M. C. Ferreira \& S. D. Rosso (Orgs.), A regulação social do trabalho (pp. 21-45). Brasília: Paralelo 15.

GIL, Antônio Carlos. Métodos e técnicas de pesquisa social. 5. ed. São Paulo: Atlas, 2008.

GIMENES, A.M; BUZZO, J.R; SANTOS, J.P. SILVA. N.C.P. Terceirizaçãa: vantagens e desvantagens para as organizações. 2016. Disponível em: https://www.inesul.edu.br/revista/arquivos/arq-idvol_48_1488488546.pdf. Acesso em: 05 de Julho de 2018.

GIOSA, L. A. Terceirização: Uma abordagem estratégica. São Paulo: ED. Pioneira, 2008.

GIRARDI, Dante. A terceirização como estratégia competitiva nas organizações. 5. ed. São Paulo: Gelre Coletânea, 2006.

KARDEC, Alan; CARVALHO, Cláudio. Gestão Estratégica e Terceirização. Rio de Janeiro: Qualimark: ABRAMAN, 2007.

LEIRIA, J. S.; SARATT, N. D. Terceirização: Uma Alternativa de Flexibilidade empresarial, São Paulo: Editora Gente, 10 ed, 2005.

MACHADO, C. C.; CALVOSA, M.V; OLIVARES, G.L. Quarteirização vs Terceirização: uma vantagem competitiva na gestão de contratos. 2016. Disponível em: https://www.aedb.br/seget/arquivos/artigos06/867_Quarterizacao\%20Seget\%20Carina.doc.pd f. Acesso em: 10 de Julho de 2018.

MARTINS, Sergio Pinto. A terceirização e o Direito do Trabalho. 12 ed. São Paulo: Atlas, 2012.

MENDONÇA, M.O. Terceirização: favorável ou não aos trabalhadores e/ou instituições ?. Rio de Janeiro, 2008. Disponível em: http://www.avm.edu.br/docpdf/monografias_publicadas/K206296.pdf. Acesso em: 05 de Julho de 2018. 
POCHMANN, Marcio. SINDEEPRES 15 anos: a superterceirização dos contratos de trabalho. Campinas: SINDEEPRES, abr. 2007. Pesquisa encomendada pelo SINDEEPRES.

QUEIROZ, Carlos Alberto Ramos de. Manual de Terceirização. São Paulo: STS Publicações e Serviços, 2004.

SILVA, José Maria da; SILVEIRA, Emerson Sena de. Apresentação de trabalhos acadêmicos. Normas e técnicas. $2^{\text {a }}$ edição. Petrópolis, RJ: Editora Vozes, 2007.

SILVEIRA, Adriano Dutra da; SARATT, Newton; MORAES, Rogério Pires. Um Passo Além da Terceirização: A transferência de atividades e tecnologia. Porto Alegre: Badejo Editorial, 2002.

SOUZA, Luiz Carlos. Direito do trabalho e terceirizações. São Paulo: Canarinho, 2017.

TRIVIÑOS, Augusto Nibaldo Silva. Introdução à pesquisa em ciências sociais: a pesquisa qualitativa em educação. São Paulo: Atlas, 2008.

\section{Como citar este artigo (Formato ABNT):}

ALVES, Nauanna Sampaio; COSTA, Antonia Valdelucia. O Processo de Terceirização de Serviços no Consórcio Águas do Ceará da Cidade de Brejo Santo-CE. Id on Line Rev.Mult. Psic., 2018, vol.12, n.42, Supl. 1, p. 552-568. ISSN: 1981-1179.

Recebido: $13 / 11 / 2018$;

Aceito: $15 / 11 / 2018$ 


\section{ENTREVISTA}

Dados do entrevistado(a):

Cargo Ocupado:

Formação:

Tempo de exercício do cargo:

Tempo de atuação na empresa:

Envolvimento no processo de terceirização:

1. Quais os principais motivos que levaram a terceirização?

2. A terceirização trouxe vantagens?

( )Aumento da qualidade dos serviços;

( )Diminuição dos custos;

( )Aumento dos lucros;

( )Melhoria na administração do Consórcio;

( )Objetivo principal do Consórcio mais focado;

( )Agilidade nas decisões;

( )Bom entrosamento dos colaboradores terceirizados com os funcionários do Consórcio;

( )Outras alternativas:

3. A terceirização trouxe desvantagens?

( )Má relação com sindicatos;

( ) Aumento da dependência de terceiros;

( )Maiores dificuldades para a administração do Consórcio;

( )Insatisfação dos colaboradores não terceirizados;

( )Piora na qualidade de atendimento aos clientes;

( )Aumento dos custos;

Outras alternativas:

4. Quais os principais obstáculos encontrados durante o processo de terceirização?

5. Qual recomendação você daria a outra empresa do ramo que quer se inserir no processo de terceirização?

6. Você acha que o Consórcio Águas do Ceará não deveria ter terceirizado algum serviço?

7. Você acha que o Consórcio Águas do Ceará deveria terceirizar mais serviços além destes já terceirizados? Quais? 